\title{
Correction to: Long-term administration of tolvaptan ameliorates annual decline in estimated glomerular filtration rate in outpatients with chronic heart failure
}

\author{
Kazuhiro Nakao ${ }^{1,2}$ - Takeshi Horio ${ }^{1}$ - Ryutaro Yoshimura ${ }^{1} \cdot$ Ryosuke Fujiwara $^{1} \cdot$ Yujiro Matsuoka ${ }^{1}$ Go Yokouchi ${ }^{1}$. \\ Haruo Nakamura ${ }^{1}$ Yuya Sakamoto ${ }^{1} \cdot$ Kohei Fujimoto $^{1} \cdot$ Yasuhiro Izumiya $^{2} \cdot$ Minoru Yoshiyama $^{2} \cdot$ Noriaki Kasayuki $^{1}$
}

Published online: 9 March 2021

(c) Springer Japan KK, part of Springer Nature 2021

Correction to: Heart and Vessels

https://doi.org/10.1007/s00380-021-01801-6

In the original publication of the article, "Ishikiriseiki Hospital" was missing in affiliation 1.

The correct affiliation should read as "Department of Cardiovascular Medicine, Ishikiriseiki Hospital, 18-28, Yayoicho, Higashi-Osaka 579-8026, Japan”.

The original article has been updated.

Publisher's Note Springer Nature remains neutral with regard to jurisdictional claims in published maps and institutional affiliations.

The original article can be found online at https://doi.org/10.1007/ s00380-021-01801-6.

Takeshi Horio

t-horio@ishikiriseiki.or.jp

1 Department of Cardiovascular Medicine, Ishikiriseiki Hospital, 18-28, Yayoi-cho, Higashi-Osaka 579-8026, Japan

2 Department of Cardiovascular Medicine, Osaka City University Graduate School of Medicine, Osaka, Japan 